\title{
Análise da cidade de Natal/RN como Destino Turístico Inteligente a partir do modelo INVAT.TUR
}

\author{
Analysis of the city of Natal/RN as Smart Tourism Destination using \\ the INVAT.TUR model
}

Daene Silva de Morais Lima - Universidade Federal do Rio Grande do Norte, Brasil (daenesmorais@hotmail.com)

Luiz Mendes Filho - Universidade Federal do Rio Grande do Norte, Brasil (luiz.mendesfilho@gmail.com)

Cynthia Harumy Watanabe Correa - Universidade de São Paulo, Brasil (cynthiacorrea@usp.br)

Verônica Feder Mayer - Universidade Federal Fluminense, Brasil (veronicamayer@id.uff.br)

\section{RESUMO}

Com a proposta de alavancar a atividade turística, o advento das Tecnologias da Informação e Comunicação (TIC) vem colaborando no desenvolvimento do conceito de Destino Turístico Inteligente (DTI). Nesse contexto, este estudo analisou os aspectos da cidade de Natal (Rio Grande do Norte) como um DTI. Para alcançar o objetivo da pesquisa foi utilizado o modelo espanhol da Comunidade Valenciana, o INVAT.TUR, que apresenta indicadores como: Governança; Sustentabilidade; Acessibilidade; Conectividade e Sensorização; Sistema de Informação; e Inovação. No que tange aos meios de investigação, mediante um roteiro semiestruturado, a pesquisa realizou entrevista com dez gestores públicos e privados, relacionados com a atividade turística em Natal. A pesquisa é de caráter descritiva e exploratória e com abordagem qualitativa, por meio da técnica de análise de conteúdo. Para auxiliar na análise dos dados, utilizou-se o software NVIVO. De acordo com os dados examinados na pesquisa e baseado no modelo INVAT.TUR, Natal encontra-se na fase embrionária como DTI. Na visão dos gestores entrevistados, apesar do elevado potencial turístico, a ausência de estratégias e ações retardam o avanço do destino. Concluiu-se, portanto, que Natal se encontra num nível abaixo do que se espera de um DTI, sendo necessárias estratégias para impulsionar o desenvolvimento do destino, por meio de um planejamento participativo com os diversos atores da cadeia produtiva do turismo. Agradecimento especial à CAPES e CNPq, órgãos de fomento, pelos recursos obtidos com o Edital Universal CNPq 01/2016 e uma bolsa de mestrado CAPES. 
Palavras-chave: Turismo, Destino Turístico Inteligente, Tecnologia, INVAT.TUR. 


\section{ABSTRACT}

With the proposal to boost the tourist activity, the advent of Information and Communication Technologies (ICT) has been collaborating in developing the concept of Smart Tourism Destination (STD). In this context, this study analyzed aspects of the city of Natal (Rio Grande do Norte) as a STD. To achieve the research objective, the Spanish model of the Valencian Community, INVAT.TUR was used, which presents indicators as Governance; Sustainability; Accessibility; Connectivity and Sensorization; Information system; and Innovation. Regarding the means of investigation, through a semi-structured script, the research interviewed ten public and private managers related to Natal's tourist activity. The study is descriptive and exploratory and with a qualitative approach through the technique of content analysis. The NVIVO software was used to assist in the analysis of the data. According to the data examined in the research and based on the INVAT.TUR model, Natal is in the embryonic phase as SDT. In the interviewed managers' view, despite the high tourism potential, the absence of strategies and actions slow the destination's progress. Therefore, the study concludes that Natal is at a level below than expected from a STD, requiring strategies to boost the destination's development through participatory planning with the various actors of the tourism production chain. Special thanks to CAPES and CNPq, funding agencies, for the resources obtained with the Universal Notice CNPq 01/2016 and a CAPES master's scholarship.

Keywords: Tourism, Smart Tourism Destination, Technology, INVAT.TUR.

\section{INTRODUÇÃO}

No panorama de inovação tecnológica no turismo global, destaca-se a perspectiva do Destino Turístico Inteligente (DTI), que tem como foco melhorar a experiência do turista, a partir da integração e utilização dos Sistemas de Inovação e das Tecnologias de Informação e de Comunicação (TIC) de forma intensiva (Gretzel, Werthner, Koo, \& Lamsfus, 2015; SEGITTUR, 2016; Mendes Filho, Silva \& Silva, 2019). O conceito de DTI abrange a aplicação de princípios das Cidades Inteligentes, inseridas no contexto de desenvolvimento participativo alicerçado em inovação tecnológica para ampliar a qualidade de vida dos habitantes.

As cidades inteligentes dispõem de uma condição infraestrutural favorável ao estabelecimento de DTI, que empregam as TIC e demais 
inovações para proporcionar prazer e experiências personalizadas ao turista (Jasrotia \& Gangotia, 2018; Cimbaljević, Stankov, \& Pavluković, 2019). Enfatiza-se que o termo "inteligente" descreve diferentes esferas, além de cidade inteligente e destino turístico inteligente, como turismo inteligente e ecossistema de turismo inteligente (Mehraliyev, Choi, \& Köseoglu, 2019).

Desse modo, a tecnologia contribui continuamente com a atividade turística, auxiliando na gestão das cidades e dos DTI (INVAT.TUR, 2015). De acordo com Boes, Buhalis e Inversini (2015), os DTI utilizam recursos tecnológicos e técnicas para gerar demanda e oferta visando ampliar o valor para o turista, bem como riqueza, lucro e benefícios para organizações e destinos.

O propósito de um DTI é proporcionar estruturas turísticas por meio do uso de recursos e tecnologias inovadoras (SEBRAE, 2016). A tendência mercadológica é que as organizações ligadas de forma direta e indireta à atividade turística adotem medidas criativas e inovadoras para aprimorar as relações dos turistas e visitantes, pois os atores envolvidos no processo buscam conectividade e experiências em tempo real (SEBRAE, 2016). Há, portanto, muitos benefícios para destinos turísticos, relatados pela literatura, com a implantação de estruturas inteligentes. No entanto, transformar um destino turístico em um DTI é um desafio para muitas cidades brasileiras. Nessa perspectiva, este estudo tem como objetivo investigar o processo de preparação de Natal, capital do Rio Grande do Norte (RN), para ser tornar um DTI, tendo como referência metodológica o modelo criado pelo Instituto Valenciano de Tecnologias Turísticas - INVAT.TUR (2015).

A escolha de Natal/RN justifica-se pelas iniciativas promovidas para ampliar a competitividade e impulsionar o processo de consolidação como um DTI. Exemplo de iniciativa foi a realização do Programa Natal Cidade Inteligente e Humana, mediante a assinatura de termo de cooperação entre a prefeitura, representada pela Secretaria Municipal de Planejamento, a Universidade Federal do Rio Grande do Norte (UFRN) e a Rede Brasileira de 
Cidades Inteligentes e Humanas (Mendes Filho, Silva \& Silva, 2019). Outra ação foi o desenvolvimento do aplicativo turístico Visit Natal, em parceria com a UFRN e a Secretaria Municipal de Turismo, com o objetivo de aprimorar a experiência do viajante no destino (Cacho et al., 2016).

O Rio Grande do Norte é um dos destinos mais procurados da região Nordeste, recebendo anualmente cerca de 2 milhões de visitantes do Brasil e do mundo. O estado destaca-se pelas belezas naturais, são 410 quilômetros de Costa Atlântica, composta por praias, dunas e lagoas. A capital Natal/RN é conhecida como a Cidade do Sol, e palco de festividades e riqueza cultural, trazendo como marco histórico a colonização holandesa e portuguesa, como também um referencial militar na II Guerra Mundial (SETUR, 2019).

Para compreender o processo de implantação de um DTI, foi escolhida uma abordagem qualitativa e coleta de dados por meio de entrevistas em profundidade. Foram entrevistados dez gestores públicos e privados de Natal/RN, com a finalidade de analisar os indicadores do modelo INVAT.TUR (2015): governança, sustentabilidade, acessibilidade, conectividade e sensorização, sistema de informação e inovação. Cada indicador serviu como recurso metodológico para avaliar quais aspectos necessitam de implementações para o desenvolvimento da capital como um DTI.

\section{DESTINOS TURÍSTICOS INTELIGENTES (DTI)}

O conceito DTI tem como parâmetro de formulação e metodologia as categorias e os pilares construídos e implementados em cidades europeias (SEBRAE, 2017). No país, o Serviço Brasileiro de Apoio às Micro e Pequenas Empresas (SEBRAE) vem promovendo o projeto Destinos Turísticos Inteligentes. No Rio Grande do Norte, por exemplo, o projeto recebe apoio do Instituto Metrópole Digital (IMD), um órgão vinculado à UFRN em parceria com a Prefeitura Municipal de Natal (Mendes Filho, Silva \& Silva, 2019). Os projetos implementam ações e estratégias baseados nos modelos de DTI. Nessa 
etapa, organizações públicas e privadas se unem com o objetivo de posicionar o destino inteligente (SEBRAE, 2017).

A Espanha alcançou resultados significativos na atividade turística na última década (INVAT.TUR, 2015). Com o intuito de manter o posicionamento, - país desenvolveu como estratégia competitiva o projeto DTI visando satisfazer necessidades atuais e futuras do mercado, dos turistas e dos visitantes, possibilitando que os turistas vivenciem uma experiência enriquecedora em tempo real (INVAT.TUR, 2015).

A proposta DTI na Espanha foi iniciada em março de 2013 pela Sociedad Estatal para La Gestión de La Innovación y las Tecnologias Turísticas (SEGITTUR), que integra o Ministério da Energia, Turismo e Agenda Digital e está vinculada à Secretaria Estadual de Turismo (SEGITTUR, 2013). Os pilares de desenvolvimento estão baseados nas novas tecnologias de informação e no desenvolvimento turístico sustentável (SEGITTUR, 2016). O desenvolvimento deve estar associado a características como acessibilidade, competitividade do setor turístico, desenvolvimento sustentável, espaço turístico inovador, gestão eficiente dos recursos, interação e integração, qualidade da experiência turística e tecnologia avançada (SEGITTUR, 2016).

O método para o desenvolvimento dos destinos, elaborado pela SEGITTUR, estimulou a definição de pilares e requisitos necessários de um sistema de gestão dos DTI. Os padrões estavam relacionados a quatro pilares: inovação, tecnologia, acessibilidade e sustentabilidade, por meio do desenvolvimento e implantação de uma política de gestão para o destino turístico, estabelecendo objetivos, metas e planos de ação (SEGITTUR, 2016).

O destino turístico é inovador quando se consolida nos aspectos de infraestrutura tecnológica, de modo a assegurar o desenvolvimento sustentável, e que seja acessível a todos, facilitando a interação e integração do visitante com o meio ambiente para melhorar a experiência no destino (SEGITTUR, 2013). Entretanto, um viés puramente tecnológico não 
é suficiente para conferir sucesso a um DTI (Gretzel, 2018; Gretzel, Ham, \& Koo, 2018).

Como observam Del Vecchio, Mele, Ndou e Secundo (2018), o objetivo final de um DTI é aprimorar a experiência em turismo, maximizando a competitividade do destino e a satisfação dos consumidores com atenção à sustentabilidade a longo prazo. Um DTI é delineado em torno de conhecimento e na oferta de uma plataforma tecnológica na qual informações podem ser trocadas instantaneamente (Jovicic, 2019), para embasar tomadas de decisões assertivas (Cimbaljević, Stankov, \& Pavluković, 2019). O turismo inteligente é uma mentalidade ou filosofia de desenvolvimento e gestão, com implicações sérias para a governança do turismo e para a orientação estratégica do destino (Gretzel, 2018).

Diante da expansão turística, deve-se desenvolver estratégias competitivas para atrair novos turistas e visitantes. Segundo Mendes Filho, Silva e Silva (2019), a tecnologia contribui como uma fonte de inovação, diferenciação estratégica e vantagem competitiva, sendo a tecnologia um instrumento-chave na cocriação de múltiplos espaços de experiência, múltiplos níveis de engajamento e redes de interação. Fornecer o conteúdo certo para o consumidor certo, especialmente em circunstâncias não planejadas, requer mais do que observar, ouvir, projetar, testar e criar o serviço esperado (Buhalis \& Sinarta, 2019). Consequentemente, a oferta de experiências personalizadas e cocriadas potencializada pelas TIC é um fator capaz de definir o sucesso de um DTI (Jasrotia \& Gangotia, 2018; Cimbaljević, Stankov, \& Pavluković, 2019).

\section{MODELOS DE DTI}

Os DTI têm como vantagem o estabelecimento de um projeto integrado à tecnologia, que representa um fator preponderante para a evolução de um destino, tornando-se uma tendência (Buhalis \& Amaranggana, 2013). Mendes Filho, Silva e Silva (2019) afirmam que o primeiro passo para um 
projeto de DTI é realizar um autodiagnóstico da realidade local, a fim de identificar as áreas que precisam de aprimoramento para estabelecer um Plano Diretor de DTI. Segundo os autores, o plano deve estar integrado aos demais planos municipais, com o objetivo de vincular a proposta a outros departamentos da gestão municipal.

O plano de DTI deve esquematizar as necessidades locais, além de identificar os pontos a serem desenvolvidos com eficiência no processo de transformação do destino. Os indicadores e critérios de mensuração podem variar conforme o destino (Freitas \& Mendes Filho, 2020). Tornar-se um DTI é uma estratégia para expandir o destino pela proposta de aprimorar a receptividade em atrativos naturais, históricos e culturais, por meio da valorização dos recursos existentes e elaboração de recursos inovadores, contribuindo com o desenvolvimento sustentável pela interação entre visitante e destino (SEGITTUR, 2016).

Baseado em revisão bibliográfica, observou-se que até o momento não existe um modelo de DTI consolidado e validado cientificamente na literatura acadêmica. Porém, autores como Jurin (2008), Ávila et al. (2015), Blanco (2015), Santos e Gândara (2016), e Sousa et al. (2016) apresentam metodologias para a transformação de um destino tradicional em um DTI. Na Espanha, referência mundial no tema (INVAT.TUR, 2015; SEGITTUR, 2016), a Agência Valenciana do Turismo do INVAT.TUR propôs um modelo de gestão chamado projeto Destinos Turísticos Inteligente da Comunidade Valenciana (DTI - CV), criado em 2014 para ampliar a competitividade dos destinos turísticos, por meio do desenvolvimento de processos, produtos e serviços, tendo como objetivo melhorar a satisfação dos turistas (INVAT.TUR, 2015). Desta forma, o modelo INVAT.TUR (2015) foi escolhido para guiar esta pesquisa. 


\section{O MODELO INVAT.TUR}

Os benefícios de um destino turístico ao se tornar um DTI são elencados em documentos do INVAT.TUR, como o Manual de Gestão de Destinos Turísticos Inteligentes e o Manual Operacional para a Configuração de Destinos Turísticos Inteligentes. Para o INVAT.TUR (2015), os benefícios são:

i. Avançar rumo ao desenvolvimento sustentável do turismo;

ii. Integrar os princípios de governança na gestão do turismo;

iii. Melhorar a eficiência na gestão do destino em todas as áreas, como marketing, ambiental, mobilidade, entre outras áreas;

iv. Reforçar a competitividade e melhorar o posicionamento do destino;

v. Explorar as oportunidades para adoção rápida das TIC pela demanda turística, como também a utilização das TIC pelas empresas de serviços turísticos;

vi. Desenvolver uma gestão de turismo mais inovadora baseada no conhecimento;

vii. Adotar um papel proativo na utilização de novas tecnologias de acordo com as necessidades de cada destino;

viii. Impulsionar o empreendedorismo e novos modelos de negócios por meio da associação das atividades turísticas com as TIC.

Os destinos turísticos da Comunidade Valenciana buscam envolver atores e ações que influenciam a atividade turística, mediante o processo de gestão eficiente e eficaz. O estudo engloba os seguintes indicadores de análise de DTI: Governança, Sustentabilidade, Acessibilidade, Conectividade e Sensorização, Sistema de Informação e Inovação (INVAT.TUR, 2015).

Os indicadores do modelo INVAT.TUR foram definidos com base na realidade dos destinos turísticos da Comunidade Valenciana, com a finalidade de auxiliar no autodiagnóstico. Entre os indicadores, como pilar estratégico está a Governança, essencial para o desenvolvimento do modelo, como também a participação das Organizações de Marketing de 
Destino. A partir dessa estrutura organizacional, derivam os pilares da Sustentabilidade e Conectividade e, assim, originam-se os outros pilares, como a Sensorização, o Sistema de Informação e a Inovação (INVAT.TUR, 2015). Um DTI busca impactar positivamente a vida dos residentes e dos visitantes, levando em consideração aspectos sociais, ambientais e econômicos intrínsecos da comunidade e que potencializam a experiência do turista.

A partir do projeto DTI-CV, proposto pelo INVAT.TUR e gerenciado pelo Instituto Universitário de Investigações Turismo (IUIT) da Universidade de Alicante, um Manual Operacional para a Configuração de Destinos Turísticos Inteligentes (2015) foi elaborado por uma equipe multidisciplinar, com profissionais e especialistas de diferentes áreas relacionadas às cidades e aos destinos inteligentes. Este documento contém características do conceito de Cidade Inteligente, como conectividade, por meio de uma rede de infraestrutura que melhore a eficiência econômica e política; desenvolvimento integrador e socialmente inclusivo; desenvolvimento urbano baseado no crescimento da economia e empresas; papel crucial para empresas de alta tecnologia e inovação; e desenvolvimento sustentável nas dimensões ambiental, econômica e sociocultural (INVAT.TUR, 2015). Em cada área citada, são atribuídos indicadores e critérios para mensuração, sendo esses critérios e indicadores adaptáveis à realidade do destino (Figura 1). 
Figura 1: Modelo INVAT.TUR

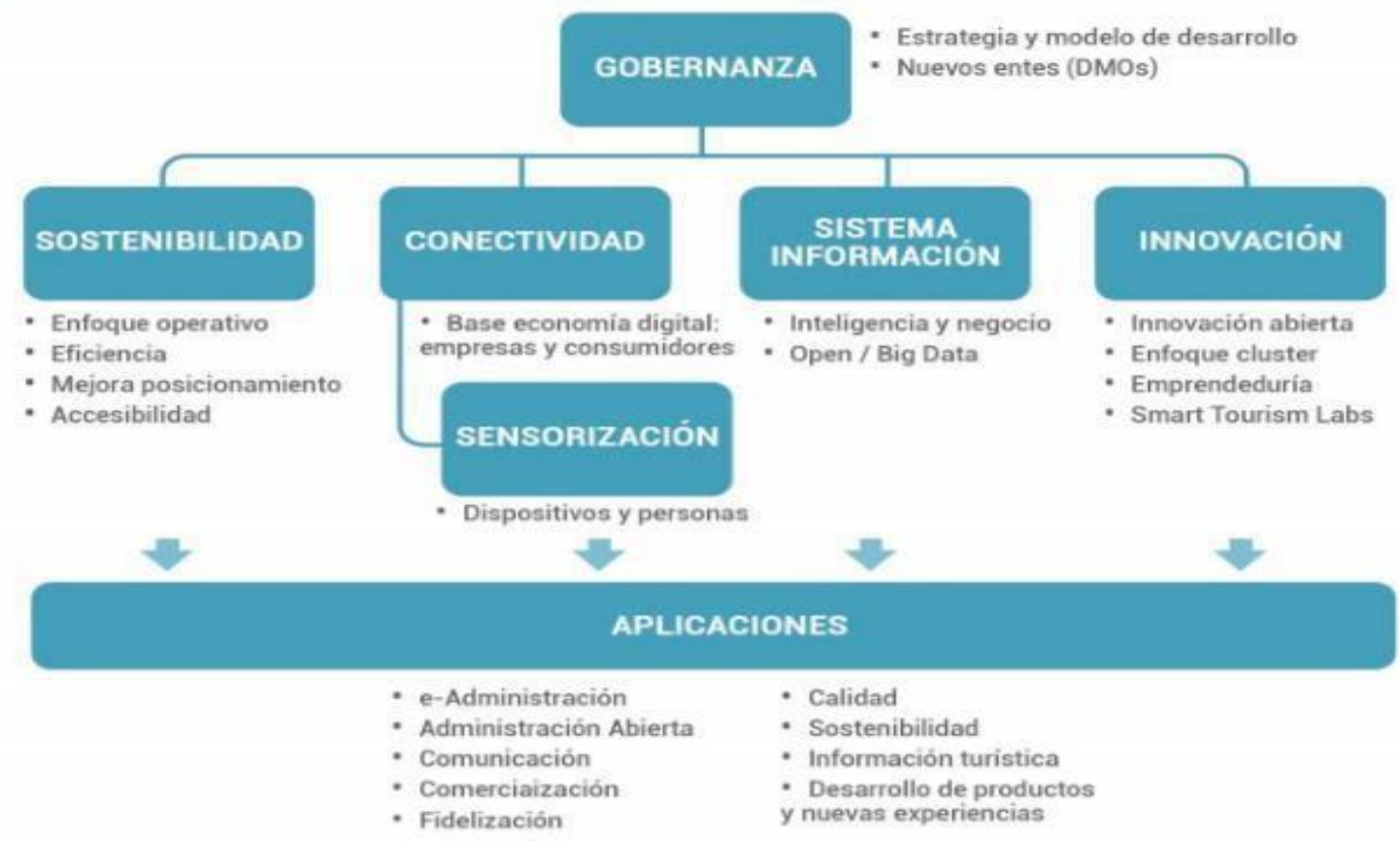

Fonte: Manual Operacional DTI-CV (2015)

\section{Indicadores do modelo INVAT.TUR}

Nessa perspectiva, apresenta-se a seguir a descrição dos indicadores que estruturam o modelo e auxiliam no autodiagnóstico dos destinos, como governança, sustentabilidade, acessibilidade, conectividade e sensorização, sistemas de informação e inovação (INVAT.TUR, 2015).

- Governança: ocorre através da participação de instituições que devem trabalhar de forma mais aberta, com comunicação ativa e linguagem acessível para os cidadãos, que devem participar de todas as fases de elaboração de políticas públicas (Blanco, 2015).

- Sustentabilidade: o desenvolvimento sustentável do turismo depende de muitos fatores relacionados ao destino urbano e turístico, que são caracterizados pela evolução urbana, o desenvolvimento imobiliário, o plano diretor do município, como também os instrumentos que o regulamentaram, ou seja, o planejamento urbano (INVAT.TUR, 2015).

- Acessibilidade: como parte da Sustentabilidade (INVAT.TUR, 2015), a Acessibilidade permite o acesso, o uso e o prazer a todos indivíduos sem 
exclusões, dando direito à igualdade de oportunidades nos ambientes, bens, serviços, produtos, tecnologias, de maneira mais segura, confortável e autônoma para todos (SEGITTUR, 2016).

- Conectividade: é um pilar fundamental para o sucesso de um DTI pela disponibilidade universal de acesso à Internet. Dois propósitos possibilitam o desenvolvimento desse indicador: para turistas e residentes, o acesso aos serviços do DTI usando dispositivos móveis, como smartphones e tablets; e para o destino turístico, fornece suporte aos serviços técnicos implantados no território, como sensores ambientais, serviços inteligentes e interativos (INVAT.TUR, 2015).

- Sensorização: consiste em coletar dados de uma magnitude objetivamente mensurável, sendo uma ampliação da conectividade (INVAT.TUR, 2015). Enquanto a conectividade se caracteriza pelo acesso à Internet, a sensorização tem como indicador o uso de dispositivos pelos visitantes. O Manual Operacional para Configuração de um Destino Turístico Inteligente da Comunidade Valenciana indica alguns elementos para aprimorar a efetividade de um sistema de sensorização (INVAT.TUR, 2015):

i. A "nuvem" - a infraestrutura responsável para fornecer serviços de publicação de dados;

ii. Sensores - os elementos capazes de coletar informações de qualquer natureza e publicá-las no sistema de nuvem.

iii. Processamento - o mecanismo responsável para coletar informações do sistema de nuvem, processá-las e publicar os resultados;

iv. Exploração - os elementos que recolhem dados publicados no sistema de nuvem, usando-os, por exemplo, para dar visualização ao público ou para tomar decisões.

- Sistema de Informação (SI): como o turismo é uma atividade de informação intensiva, ao envolver várias áreas - operadoras de turismo, agências de viagens, companhias aéreas, hotelaria, alimentos e bebidas, 
lazer e entretenimento, guiamento turístico, locadoras de veículos, área de transporte -, os SI são indispensáveis para a expansão setor (Ramos, Mendes Filho \& Lobianco, 2017). Para esses autores (2017, p. 22), o SI consiste em "um sistema por meio do qual os dados são obtidos, processados e transformados em informações de forma esquematizada e ordenada para servirem de subsídios ao processo de tomada de decisões".

- Inovação: é essencial para manter a competitividade do destino turístico através de técnicas que permitam a melhoria de serviços, processos, métodos de marketing, gestão do destino e relacionamento com residentes e visitantes (SEGITTUR, 2016).

\section{PROCEDIMENTOS METODOLÓGICOS}

Esta pesquisa tem como proposta analisar os aspectos de um DTI, por meio de uma análise da cidade de Natal/RN. O estudo consiste em uma pesquisa exploratória, por sua natureza de investigação, visando à ampliação do conhecimento teórico sobre a temática. Conjuntamente, é uma pesquisa descritiva (Cervo \& Bervian, 1996), por ter como característica descrever os aspectos de um DTI, segundo o modelo do INVAT.TUR.

O estudo se apoiou em pesquisa documental a partir do Plano Diretor de Natal e materiais produzidos pelo INVAT.TUR (2015), em parceria com órgãos espanhóis: a) Guia de Implantação de Destinos Turísticos Inteligentes da Comunidade Valenciana, elaborado pelo Generalitat Valenciana e a Universidade de Alicante; e b) Manual Operacional para a Configuração de Destinos Turísticos Inteligentes, produzido pela Generalitat Valenciana e o IUTT. Importante citar que o Guia de Destinos Turísticos Inteligentes: construindo o futuro, elaborado por Ávila et al. (2015), também contribuiu na construção teórica da pesquisa. Esse documento foi criado com o objetivo de realizar as ações necessárias para a preparação do Relatório Específico no âmbito do Plano Nacional de Cidades Inteligente da Agenda Digital para a Espanha. 
A etapa da coleta de dados foi a mais prolongada, por coincidir com eventos que dificultaram a conclusão do cronograma previsto. Entre esses eventos, cita-se a realização da Copa do Mundo de Futebol (Rússia), e em seguida o processo eleitoral no Brasil e a transição dos governos (Eleições 2018). Diante dessa dificuldade, essa etapa percorreu entre junho de 2018 e abril de 2019. O método da amostragem utilizado na pesquisa é de caráter não-probabilístico, por conveniência, pois visto que a população amostral foi selecionada de acordo com elementos representativos do público-alvo, com base nos objetivos de estudo.

No que tange aos meios de investigação, foram realizadas entrevistas semiestruturadas com gestores públicos e privados. Para tratar os dados, os indicadores do modelo INVAT.TUR foram utilizados como categoria de análise visando identificar barreiras, oportunidades e contribuições para o desenvolvimento do destino turístico Natal/RN como um DTI.

A pesquisa tem abordagem qualitativa, ainda conhecida como abordagens hermenêuticas, reconstrutivas ou interpretativas (Flick, 2009). Esse tipo de pesquisa dispõe de características próprias, como a compreensão, a interpretação e o entendimento do pesquisador, que utiliza o texto como material empírico, e analisa a construção social da realidade em que o estudo está inserido (Denzin \& Lincoln, 2005, Flick, 2009). A abordagem qualitativa se caracteriza como fonte direta para coleta de dados, interpretação de fenômenos e atribuição de significados (Vargas \& Maldonado, 2001; Silva \& Menezes, 2001).

Conforme Dencker (2000), antes da aplicação definitiva do instrumento de coleta de dados, deve-se realizar um pré-teste ou estudo piloto. Este serve para evidenciar falhas na redação do roteiro de entrevista, a complexidade das questões, a imprecisão na redação, a irrelevância de algumas questões, entre outros aspectos para aprimorar a coleta de dados. Nessa perspectiva, realizou-se o estudo piloto em agosto de 2018, com um gestor de uma fundação de direito privado ligada à cadeia produtiva do 
turismo na cidade do Natal/RN. Após o piloto, julgou-se necessário incluir uma questão, passando de 18 para 19 perguntas.

Desta forma, o roteiro de entrevista semiestruturado contou com 19 perguntas abertas baseadas nos seis indicadores do modelo INVAT.TUR (2015), e foi aplicado a gestores de órgãos públicos e organizações privadas considerados estratégicos para atender ao objetivo da pesquisa (Tabela 1).

Tabela 1: Descrição dos entrevistados

\begin{tabular}{c|l|c}
\hline ENTREVISTADO & ORGANIZAÇÃO & CARGO \\
\hline GESTOR 1 & Natal Convention Bureau & Coordenador \\
\hline GESTOR 2 & Agência de Viagens (regional) & Gerente \\
\hline GESTOR 3 & Secretaria de Turismo do RN & Secretário \\
\hline GESTOR 4 & Terminal Rodoviário de Natal & Gerente \\
\hline GESTOR 5 & Empresa Potiguar de Promoção Turística & Diretor \\
\hline GESTOR 6 & Companhia Aérea (nacional) & Gerente \\
\hline GESTOR 7 & Secretaria Municipal de Turismo & Secretário \\
\hline GESTOR 8 & ServiçO Brasileiro de Apoio às Micro e & Gerente \\
\hline GESTOR 9 & Aeroporto de Natal & Gerente \\
\hline GESTOR 10 & Hotel Escola Barreira Roxa (SENAC) & Gerente \\
\hline
\end{tabular}

Fonte: Elaborado pelos autores (2019)

Um Termo de Consentimento Livre e Esclarecido foi apresentado aos entrevistados para esclarecer os objetivos e a importância da pesquisa, além de garantir procedimentos éticos como a afirmação de que o nome do participante não seria revelado, concedendo maior liberdade de expressão nas respostas. Um Termo de Autorização para Gravação de Voz também foi elaborado com o objetivo de dar transparência à pesquisa, sendo informado o motivo da gravação, assegurando aos entrevistados que o conteúdo seria utilizado apenas para fins acadêmicos.

No que concerne ao tratamento dos dados, foi utilizada a análise de conteúdo que, conforme Bardin (2011), envolve procedimentos metodológicos divididos em fases: pré-análise, exploração do conteúdo, 
coleta de dados, codificação das respostas, tabulação e interpretação dos dados. A análise dos dados foi realizada com auxílio do software NVIVO (versão 12.0), que suporta métodos qualitativos e variados de pesquisa, como entrevistas, respostas abertas de pesquisa, artigos, mídia social e conteúdo web (NVIVO, 2019). O que motivou a utilização do NVIVO foi a funcionalidade oferecida pelo programa, que proporcionou uma organização, estruturação e codificação dos dados coletados, permitindo uma melhor compreensão e análise dos resultados da pesquisa.

\section{ANÁLISE E DISCUSSÃO DOS RESULTADOS}

Neste tópico, inicia-se a análise e discussão dos dados coletados, tanto no que concerne às fontes secundárias da primeira fase da pesquisa, em termos bibliográficos e documentais, como em relação aos dados primários da segunda fase, quando se partiu a campo. Na sequência, os indicadores do modelo INVAT.TUR são tratados no destino Natal/RN.

\section{Governança}

Como acontece nas Cidades Inteligentes, os DTI são impulsionados para repensar a gestão governamental. Dirks e Keeling (2009) afirmam que o desenvolvimento estratégico da cidade é o elemento fundamental para se tornar uma cidade inteligente, e assim ocorre com os destinos. Para um destino se tornar um DTI, é necessário repensar as estratégias de políticas públicas e a eficiência de uma gestão governamental (INVAT.TUR, 2015).

O modelo do INVAT.TUR segue os princípios básicos da Governança europeia, que estabelece cinco princípios básicos: Abertura, Participação, Responsabilidade, Eficiência/Eficácia e Coerência. Estes princípios são aplicáveis em todas as esferas políticas, sendo uma referência básica para analisar a evolução para Cidades Inteligente, e, portanto, para os DTI (INVAT.TUR, 2015). 
Luque-Gil, Zayas-Fernández e Caro-Herrero (2015) advogam que estudos com o objetivo de coletar dados podem maximizar os impactos positivos na gestão do destino. Os resultados alcançados embasarão discussões relevantes para a elaboração de um observatório turístico, como contribuirão com iniciativas para a expansão, compreensão e aplicação prática do conceito. Essa metodologia é aplicada em alguns destinos espanhóis.

Em relação aos dados desta pesquisa em Natal/RN, todos os entrevistados alegaram que a atividade turística é de suma importância para a cidade, contribuindo para a promoção de um desenvolvimento econômico, sociocultural e ambiental. Entre as opiniões dos entrevistados, destacaram-se:

O Turismo, quando bem gerido, movimenta de forma rápida mais de 50 setores da economia, incluindo também os informais, artesãos e uma vasta cadeia produtiva, impactando positivamente nos micro e pequenos negócios (Gestor 10).

Quando o turismo é colocado como prioridade para uma gestão, os demais pontos são tratados também como prioridade, o desenvolvimento econômico é trazido como consequência na geração de emprego e renda proporcionada diretamente pela atividade, assim como a valorização cultural e ambiental são promovidas, pois ambas compõem os atrativos que são oferecidos para os turistas que visitam determinada região (Gestor 1).

De forma unânime, os entrevistados afirmaram notar uma deficiência no planejamento do turismo em Natal/RN, como enfatizado a seguir:

Independente do planejamento municipal e estadual, recém finalizados, pouco se tem colocado em prática [sobre] as ações que devem ser tidas como prioritárias para o desenvolvimento da atividade turística e promoção do destino de forma eficaz. Quando olhamos para estados vizinhos, como Ceará e a própria Paraíba, vimos que estamos cada vez 
mais ficando para trás em muitas questões, principalmente no que se refere à promoção e atração de investimentos (Gestor 1).

Considero o planejamento turístico em Natal ainda fraco, comparado a outras cidades do Nordeste estamos muito atrás principalmente em relação à promoção do destino. Apesar da organização que vem sendo feita nos últimos anos a atividade turística não tem a atenção que merece, muita coisa ainda é feita no improviso (Gestor 4).

Por sua vez, quatro gestores asseguraram não ter conhecimento na íntegra do Plano Diretor de Natal (PDN), o principal marco regulatório regido pela Lei Complementar $n^{\circ}$ 082, de 21 de junho de 2007. O PDN direciona a gestão dos espaços públicos, sendo um documento de orientação para os agentes públicos e privados que atuam na produção e gestão do espaço urbano. Esta falta de conhecimento evidencia a baixa participação e envolvimento de stakeholders nos processos locais de planejamento, um dos principais elementos da governança de um DTI (Wilhelm \& Ruhlandt, 2019).

A última versão do PDN é de 2007, e desde 2017 se iniciou uma revisão, porém, até 2019 a nova proposta não havia sido concluída (Prefeitura Municipal de Natal, 2019). O PDN é o instrumento básico da política de desenvolvimento urbano sustentável do município, cujo objetivo é desenvolver as funções sociais e ambientais da cidade, bem como a propriedade, garantindo um uso socialmente justo e ecologicamente equilibrado do território (Prefeitura Municipal de Natal, 2019).

Todos os gestores públicos entrevistados afirmaram que há uma grande deficiência em relação às políticas públicas para o turismo, inclusive, dois entrevistados apresentaram respostas similares ao comentar que 0 orçamento está apertado nos últimos anos, sendo muito difícil executar alguns planos.

Os gestores públicos ainda citaram o Plano de Desenvolvimento Integrado do Turismo Sustentável (PDITS) e o Programa de Ação para o Desenvolvimento do Turismo do Nordeste (PRODETUR/NE) como ações de 
desenvolvimento do turismo local. Como o estudo se restringiu à Natal/RN, observou-se que há uma dependência macro de estratégias e políticas públicas por parte do estado:

As metas por meio do PDITS e do PRODETUR são os principais investimentos para todos os polos turísticos do estado do Rio Grande do Norte. Levando em consideração a cidade de Natal inserida no Polo Costa das Dunas, [ela] está inserida no plano de desenvolvimento turístico (Gestor 3).

O PRODETUR encontra-se em fase de expansão em todo o Nordeste, não sendo diferente no Rio Grande do Norte. Estima-se investimentos para o setor em nível estadual, e que consequentemente será um avanço para a capital Natal. O turismo é considerado de grande relevância para o desenvolvimento local, e estamos focados em ações e projetos para impulsionar o setor (Gestor 5).

O PDITS tem como meta definir uma estratégia para o desenvolvimento da atividade turística no estado e, paralelamente, servir de "marco lógico" para o PRODETUR/NE. Os governadores dos estados do Nordeste criaram o PRODETUR/NE com o apoio do governo federal e financiamento do Banco Interamericano de Desenvolvimento (BID), visando desenvolver e consolidar a atividade turística, aproveitando o potencial natural existente e, ao mesmo tempo, garantindo a sustentabilidade econômica por meio de uma atividade crescente mundialmente, como forma de reduzir e eliminar as desigualdades sociais entre as regiões do país (Prefeitura Municipal de Natal, 2019).

Ainda no tocante à Governança, na opinião dos entrevistados, a infraestrutura turística da cidade do Natal/RN tem problemas ou deficiências (Figura 2). Para Femenia-Serra e Perea-Medina (2016), a perspectiva de desenvolvimento de um destino tradicional em um DTI está relacionada à gestão dos destinos que envolve orçamento e infraestrutura, considerados aspectos essenciais no processo de transformação rumo a um turismo inteligente. 
Figura 2: Principais problemas na infraestrutura turística

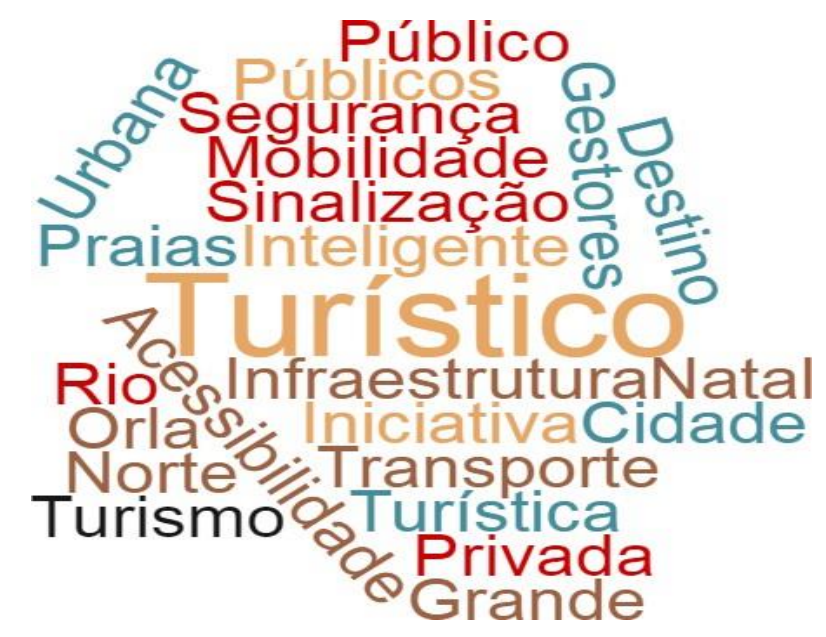

Fonte: Dados da Pesquisa (2019)

A gestão do turismo deve basear-se num processo de planejamento, com uma metodologia para incluir a participação social, e assim alcançar um maior grau de consenso entre os diversos agentes. Os DTI caracterizam-se por uma nova gestão para torná-los eficientes, proativos, integradores do produto turístico local e capazes de gerir a complexidade e transversalidade da oferta local. Essa nova gestão reforça a necessidade de transformar o modelo tradicional de gestão turística em destinos inteligentes.

Diante das estratégias iniciadas na Comunidade Valenciana, o INVAT.TUR propôs a elaboração de um plano estratégico, baseado na governança colaborativa, reunindo ideias, sugestões e opiniões, por meio da participação e contribuição de todos os atores do setor turístico valenciano. O Plano Estratégico de Turismo da Comunidade Valenciana 2020-2025 tem como proposta tornar o DTI-CV um destino turístico autêntico e seguro, em que os visitantes escolham o destino por características como hospitalidade, qualidade de vida dos residentes e pelos valores éticos, gerida de forma colaborativa e corresponsável, tornando-se um território inteligente, inclusivo, inovador e sustentável (INVAT.TUR, 2020).

Atualmente, o Plano Estratégico de Turismo da Comunidade Valenciana 2020 - 2025 está na fase inicial de participação social e consenso com os 
agentes turísticos. Devido à atual situação mundial, a pandemia da Covid19, as atividades estão sendo desenvolvidas por meio de encontros telemáticos. Dos atores convidados para essa fase, destacam-se Confederações Empresariais, Sindicatos, Organizações de Consumidores, Federação Autônoma das Associações de Bairro, Universidades Valencianas, Rede DTI-CV, especialistas ligados ao "Programa CV O Destino Seguro", membros da Comissão de Turismo entre outros (INVAT.TUR, 2020).

Comparando-se a gestão do turismo de Natal/RN com o modelo INVAT.TUR, nota-se que não há métodos e práticas de Governança claramente definidas e implantadas. Percebe-se, ainda, segundo os relatos, ser necessária a elaboração de um plano estratégico participativo e transparente, no qual sejam traçados objetivos e desenvolvidas ações coordenadas, que possam ser monitoradas e controladas pelos gestores do destino.

\section{Sustentabilidade}

O desenvolvimento sustentável do turismo depende do modelo de destino urbano e turístico, pois a evolução urbana, o desenvolvimento imobiliário-turístico e o planejamento urbano influenciam no avanço dos destinos. No contexto das Cidades Inteligentes e dos DTI, a Sustentabilidade apoia-se em um tripé que engloba o aspecto econômico, ligado à competitividade; o social, relacionado à qualidade de vida; e o do meio ambiente, com uma gestão eficiente dos recursos naturais (INVAT.TUR, 2015).

Conforme a OMT (2004), o desenvolvimento sustentável do turismo é um processo contínuo que requer monitoramento constante das atividades, reduzindo os impactos negativos e potencializando os benefícios, por meio de medidas corretivas. Esse processo requer a participação e o comprometimento de todos os atores, principalmente o poder público que deve incentivar e apoiar o processo, estimulando a participação da sociedade por meio da construção de consensos. Destarte, os produtos 
turísticos sustentáveis são desenvolvidos em equilíbrio com o meio ambiente e as particularidades do destino, por meio da sustentabilidade e conservação de recursos naturais e patrimônio, bem como incentivando o incremento econômico da comunidade local (INVAT.TUR, 2015).

Este tópico é significativo para analisar as concepções de sustentabilidade implementadas em Natal/RN, por meio da compreensão de alguns aspectos como proteção e melhoria da paisagem e do meio ambiente urbano, como ainda analisar a situação sobre a gestão sustentável de recursos públicos disponíveis para promover a atividade turística. No entanto, nove dos dez entrevistados relataram desconhecer projetos de Sustentabilidade na cidade. Corroborando os dados obtidos por Mendes Filho, Silva e Silva (2019), de que o segmento de Sustentabilidade turística apresenta resultado nulo, sem a possibilidade de caracterização como um DTI nesse quesito.

O SEBRAE/RN segue prestando consultoria a empreendimentos de pequeno e médio porte quanto à implantação da Energia Solar Fotovoltaica. Também com foco na sustentabilidade, vem auxiliando com estudos de viabilidade, da fase inicial até a implantação, com orientações para o licenciamento ambiental de empresas turísticas.

O desenvolvimento sustentável do turismo é relevante para a preservação do destino em face da crescente conscientização do impacto ambiental. A demanda exige da gestão do destino a promoção de políticas públicas para manter a sustentabilidade. Em Natal/RN, embora o resultado aponte que até o momento não houve evolução no aspecto de Sustentabilidade, o PDN (2007) dispõe no Artigo 3', Inciso I, o seguinte texto:

A preservação, proteção e recuperação do meio ambiente e da paisagem urbana, com vistas a garantir, além da manutenção equilibrada dos recursos naturais, qualidade de vida para os habitantes do Município, incentivo à atividade econômica sustentável e proteção 
ao patrimônio histórico e cultural da cidade (Prefeitura Municipal de Natal, 2007).

\section{Acessibilidade}

Quanto ao conceito de Acessibilidade, todos os entrevistados informaram desconhecer projetos nessa linha. Importante destacar a opinião do Gestor 2, quando questionado sobre os projetos que vem sendo desenvolvidos na cidade em termos de Acessibilidade:

Desconheço. Sei, porque vivencio na minha atividade, as exigências de acessibilidade para a iniciativa privada que são constantes, mais quando se volta para o poder público, não vemos uma calçada reta.

Diante disso, foi necessário aprofundar a leitura no PDN vigente, no qual há uma diretriz no Artigo $3^{\circ}$, Inciso $\mathrm{V}$, para a adequação dos espaços coletivos à acessibilidade urbana para todos os seus cidadãos. Já no Artigo $6^{\circ}$, Inciso V, indica-se a qualidade da habitação adequada ao uso humano, com salubridade, segurança e acessibilidade de serviços e infraestrutura urbana. Destarte, apesar de ser uma responsabilidade do setor público, a Acessibilidade ainda não é considerada suficiente nos dias atuais.

A acessibilidade em um DTI deve trabalhar na perspectiva integral, promovendo a criação de ambientes acessíveis sob duas abordagens: acessibilidade física e digital (INVAT.TUR, 2015). A acessibilidade é entendida como a eliminação ou no mínimo a redução de obstáculos e barreiras que assegurem acesso universal aos cidadãos. O turismo é um direito social e fundamental para todos, o que se traduz no direito de igualdade de oportunidades, não discriminação e a integração social de um expressivo segmento da população.

Um estudo realizado pelo MTur e pela Secretaria de Direitos Humanos, para analisar o Perfil do Turista da Pessoa com Deficiência (2013), apresentou índices dos municípios que precisam avançar no quesito acessibilidade. 
Conforme essa pesquisa, o destino Natal estava classificado como Acessibilidade mediana (MTur, 2013). A visão do MTur (2013) é de que a atividade turística seja tratada como uma via de inclusão, de maneira que o turismo social seja uma forma de turismo acessível para todos os cidadãos, sem discriminação de acessos de qualquer natureza. Como resultado, o MTur vem apoiando projetos que viabilizem a acessibilidade urbana, a adaptação de atividades turísticas, a sensibilização e disseminação de orientações nos diversos setores ligados direta e indiretamente à atividade turística (MTur, 2015).

A posição do MTur vai ao encontro da teoria dos autores Santos, Souza Neto, Pereira, Gândara e Silva (2016), que propõem a implementação de planos locais de acessibilidade urbana, objetivando a minimização de entraves.

Entre os principais problemas urbanos citados nas entrevistas, vale destacar a insegurança, violência, sinalização turística precária, patrimônio histórico e cultural sem a devida atenção, deficiência na limpeza urbana e desprovimento na mobilidade, pavimentação, transporte público e acessibilidade (Figura 3).

Figura 3: Principais problemas urbanos

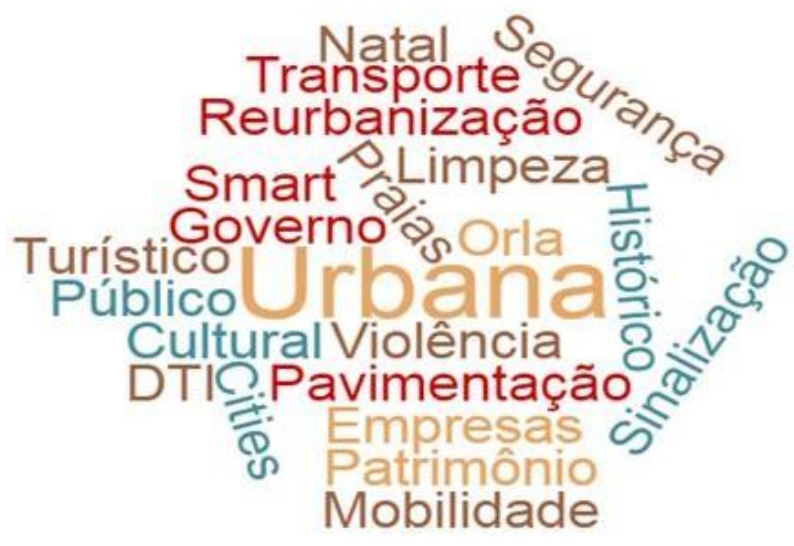

Fonte: Dados da Pesquisa (2019)

A Comunidade Valenciana está implementando o modelo Smart Natural Space, alinhado aos aspectos de Segurança, Acessibilidade 
e Sustentabilidade, adaptando áreas naturais do projeto DTI, tendo como objetivo identificar riscos e analisar oportunidades, por meio da realidade atual e a prospecção do que se espera para o futuro (INVAT.TUR, 2020). O modelo leva em consideração as necessidades dos turistas e residentes, por meio de atividades, produtos e serviços oferecidos pelos espaços naturais.

\section{Conectividade e Sensorização}

A Conectividade e Sensorização é um pilar fundamental no sucesso de um DTI, por contribuir com turistas e residentes, consistindo em disponibilizar de forma universal acesso aos serviços inteligentes e interativos a partir de dispositivos móveis e sensores (INVAT.TUR, 2015).

O modelo INVAT.TUR apresenta características para implantação desse pilar por meio da economicidade sustentável, acesso gratuito a turistas e residentes, velocidade de banda larga razoável e geograficamente localizável. O processo de implantação deve se adequar ao destino, de forma a cumprir com as características mencionadas, sendo necessário analisar as opções tecnológicas no território e a aplicabilidade para o destino turístico (INVAT.TUR, 2015).

Um estudo de Thomaz, Biz e Gândara (2013) expôs que ações de marketing em redes sociais contribuem para a promoção do destino devido à gratuidade e facilidade de acesso. Logo, as ferramentas tecnológicas e as redes sociais utilizadas pelos turistas geram dados capazes de aprimorar a gestão de um destino (Thomaz, Biz, Bettoni, Mendes-Filho, \& Buhalis, 2017). Comparando o estudo com a realidade de Natal/RN, na categoria Conectividade e Sensorização, a cidade não se posicionou como um DTI. Ademais, os dez gestores reclamaram da inexistência de wifi gratuito e seguro para os turistas e residentes. Logo, o acesso à internet gratuita em pontos turísticos e em áreas públicas (shoppings, praças, parques urbanos de visitação, aeroportos e espaços públicos) é estratégico para o desenvolvimento de uma Cidade Inteligente e de um DTI. 
Por sua vez, alguns gestores privados informaram que nos empreendimentos onde atuam é disponibilizado acesso gratuito à rede, enquanto outros limitam o acesso por senha ou mediante check-in nas redes sociais. No caso dos gestores públicos, estavam sem acesso à internet e sem telefone corporativo nos respectivos órgãos no momento. Segundo um entrevistado, "Os telefones foram cortados por falta de pagamento dos serviços".

Na visão dos gestores, é de suma importância ter um aplicativo com foco no turista/visitante, porém, quatro afirmaram desconhecer aplicativos projetados para impulsionar a atividade na cidade. Todavia, o destino dispõe de aplicativo focado no turismo. O Find Natal foi o primeiro aplicativo criado em 2015 por estudantes e professores da UFRN e acessado via plataforma Android (Cacho et al., 2016). Em 2017, foi lançada uma nova versão que recebeu o nome de Visit Natal, tornando-se o aplicativo oficial de turismo. O Visit Natal foi idealizado durante dois anos no Programa Natal Cidade Inteligente e Humana, numa parceria entre a Prefeitura Municipal de Natal e a UFRN, por intermédio do Instituto Metrópole Digital (Mendes Filho, Silva, \& Silva, 2019).

No tocante à Conectividade e Sensorização, destaca-se a percepção do Gestor 8:

Conheço o aplicativo Visit Natal, mas não estou sabendo como anda a atualização e manutenção do mesmo. Pessoalmente questiono a eficácia de aplicativos em destinos turísticos, pois ainda aposto em plataformas da Web, por ser mais dinâmicas e de fácil acesso, uma vez que independe de instalar nada no celular. O aplicativo tem a tendência de ser instalado antes e durante a viagem, mas depois da viagem será desinstalado. Aposto em uma página da web, munida de boas informações e atualizada, sem dúvida os custos são inferiores do aplicativo, em relação ao desenvolvimento e manutenção. 
Para os gestores, as redes sociais são instrumentos significativos para promover o destino Natal, mas devem ser gerenciadas de forma profissional e planejada para colaborar com o crescimento turístico.

No que tange à Conectividade e Sensorização do DTI-CV, pode-se citar o avanço na elaboração de ferramentas tecnológicas. Dois projetos foram realizados: Apps para Viagens e Monitor de Reservas. Atualmente três outras ferramentas estão em desenvolvimento: Painel de Redes Sociais (RRSS Dashboard), DTI Autodiagnóstico (DTI Self-Diagnosis) e Análise Social dos Destinos ( Social Analytics CV Destinations) (INVAT.TUR, 2020).

\section{Sistema de Informação (SI)}

Os SI representam parte de uma gestão inteligente no contexto de um DTI e dependem de atores ligados ao destino para a produção, geração e compartilhamento de dados turísticos. Há vários aspectos dos SI que afetam padrões de consumo de turistas, incluindo a experiência, a satisfação e as intenções de comportamento (Mehraliyev et al., 2020).

Conforme o modelo INVAT.TUR (2015), os principais atores desse pilar são:

i. Gestores de destino - de caráter público e que tomam decisões com base nos dados disponíveis, executando ações de modo que o destino cumpra os objetivos como DTI;

ii. Iniciativa pública - para poder atender aos objetivos da organização, precisa analisar os dados disponíveis e fornecer indicadores para melhorar a competitividade;

iii. Turistas - a gestão inteligente de dados de um DTI deve girar em torno de pessoas, e deve fornecer dados para que os turistas tenham experiência turística antes, durante e após a viagem.

O turista quer aproveitar ao máximo os atrativos disponíveis durante a viagem, por meio da integração e interação dos dados. Além disso, os 
dados gerados pelos turistas são relevantes para análise de outros atores durante todo o ciclo da viagem. Gestores e empreendedores do destino podem tomar decisões apoiados nesses dados, aumentando a satisfação do visitante.

As TIC são imensuráveis quando comparadas aos meios tradicionais de comunicação, e, segundo Thomaz, Biz e Gândara (2013), a produção de conteúdo expandiu com o advento das redes sociais. E, no turismo, O compartilhamento de experiências contribui na estruturação de um potencial DTI (Gomes, Gândara, \& Ivars-Baidal, 2017).

As TIC não se restringem a uma única ferramenta tecnológica, uma vez que estão associadas à capacidade de geração de conhecimento de um destino (Thomaz, Biz, \& Gândara, 2013). Portanto, elas desempenham um papel relevante na gestão dos destinos turísticos, impulsionando na promoção e evolução do marketing, mediante o acesso a informações e compartilhamento de conhecimento.

Quanto ao estudo sobre Natal/RN, todos os gestores públicos consideraram as TIC importantes para o desenvolvimento turístico da cidade, como as seguintes opiniões:

É indispensável, por contribuir com ações mais direcionados para a atividade turística. Fico alegre em saber que as tecnologias da comunicação vêm sendo essencial nos dias atuais, e o turismo precisa tê-la como aliada, pois o turista é conectado antes a viagem, posta fotos durante a viagem e ainda tem as postagens pós viagem, como é o caso daquele \#TBT (Gestor 6).

A TIC é fundamental, e deve caminhar lado a lado com o turismo, por contribuir na capitação e análise de dados, e com isso o direcionamento do 'novo perfil do turista', que é conectado durante os ciclos da viagem (antes, durante ou depois). Importante que os destinos tenham esse suporte tecnológico, pois como já citei, contribuir em captor dados, e após gerados poderá direcionar a promoção e divulgação do destino (Gestor 8). 
A TIC é muito importante e indispensável para o desenvolvimento turístico da cidade do Natal, já que está ligada a diversos processos, e pode ser grande aliada para a unificação de dados e geração de informação (Gestor 10).

Apesar das visões de gestores sobre a contribuição das TIC, só três entrevistados afirmaram que a organização onde trabalham utiliza alguma ferramenta para gerar banco de dados/informação. Dropbox e Google Drive estavam entre as ferramentas nomeadas. $\bigcirc$ Gestor 8 comentou que a organização investia alto em mídia impressa para uma determinada campanha de divulgação. Porém, quando encerrava a campanha, todo o material restante era descartado. Com as TIC passou a desenvolver websites e redes sociais como estratégia de promoção do turismo. Também foram citadas ferramentas de front office, Global Distribution System e back office em empreendimentos turísticos privados.

Na Comunidade Valenciana, foi instalado no Invattur Smart Lab, o projeto Smart Data Office (SDO), e está integrado ao Turismo Comunitário Valenciano (TCV) e ao Smart Tourism Destinations (DTI - CV). 0 principal objetivo do projeto é coletar e analisar informações do perfil e do comportamento do turista que visita a Comunidade Valenciana. Com o intuito de avançar no projeto, foi aberto edital de licitação para contratação de um Sistema de Inteligência Turística da Comunidade Valenciana, denominado: DATATUR4CV. Neste momento, está na fase de prospecção de propostas (INVAT.TUR, 2020; Plataforma de Contratación del Sector Público, 2020).

\section{Inovação}

A Prefeitura Municipal de Natal está buscando um ambiente de inovação, promovendo parcerias com a UFRN, por meio do Instituto Metrópole Digital, o Instituto Federal de Educação, Ciência e Tecnologia do Rio Grande do Norte, a Universidade Potiguar, utilizando esses ambientes 
como incubadoras para desenvolver programas em diversas áreas, como segurança e cidades inteligentes (Mendes Filho, Silva, \& Silva, 2019).

Somente quatro entrevistados alegaram conhecer algum projeto turístico desenvolvido na cidade. Todos os gestores disseram conhecer os conceitos de Cidade Inteligente e DTI a partir do SEBRAE. Porém, em relação à perspectiva de Natal/RN como um DTI, todos afirmaram que há uma tendência nesse caminho, mas hoje não visualizam o destino como inteligente, como indica o Gestor 8:

O conceito DTI é inovador, e Natal carece de infraestrutura básica, como segurança, acessibilidade, sinalização e informação. Acredito que se relegar o preceito de um DTI, tem que cuidar do básico para se tornar realmente um destino com essa proposta de inteligente.

Entre os principais entraves que impedem Natal/RN a se tornar um DTI, destaca-se os seguintes trechos:

Natal poderá se tornar um DTI, porém é necessário ser elaborado um planejamento estratégico, uma vez que os principais entraves estão ligados aos atuais problemas urbanos (segurança, mobilidade e acessibilidade). Também precisa melhorar os projetos voltados para inovação e tecnologia (Gestor 2).

Acredito que Natal ainda será um destino inteligente, porém os entraves são vários, desde total acessibilidade na cidade à competitividade eficiente do destino, buscando promover a experiência do turista de forma única, com a qualidade dos serviços eficientes e um desenvolvimento sustentável no uso dos recursos naturais (Gestor 3).

O principal entrave é o baixo orçamento da Secretaria de Turismo Municipal. O recurso financeiro não é digno de alavancar qualquer novo trabalho de impacto relevante à atividade turística. Diferente de outros destinos que priorizam a atividade turística como importante setor econômico para o desenvolvimento local (Gestor 7).

A dinâmica global de inovação pode se tornar, portanto, uma ameaça às empresas e destinos turísticos tradicionais. Segundo Mehraliyev et al. 
(2020) há uma série de iniciativas inovadoras relacionadas ao conceito de DTI, com o uso das mais recentes tecnologias como internet das coisas, computação em nuvem, redes neurais, entre outras.

Nesse panorama, o desenvolvimento de DTI atua como um estímulo e um elemento para incrementar a inovação. No entanto, a transformação de destinos em ambientes inovadores requer um processo longo e complexo para os municípios (INVAT.TUR, 2015).

A Agência Valenciana de Turismo desenvolveu nos últimos anos diferentes linhas estratégicas para melhorar a inovação (INVAT.TUR, 2015), por exemplo:

i. Assistência financeira para a implementação e certificação de sistemas de gestão e para a realização de planos e projetos;

ii. Assistência financeira a empresas e associações para promoção e marketing online;

iii. Iniciativas de marketing de mídia social e acessibilidade (praias acessíveis);

iv. Orientação para inovação da Rede de Informação Turística;

v. Suporte para treinamentos visando impulsionar o conceito inovação;

vi. Criação do Instituto Valenciano de Tecnologias;

vii. Desenvolvimento da plataforma de marketing e aplicativos de viagens.

Cinco gestores afirmaram que a organização representada contribui com ações e estratégias para tornar Natal/RN um DTI, como ilustrado:

Por meio da promoção do destino, e tem como missão apresentar uma cidade que possua todas as condições necessárias para captar eventos de grandes proporções, apresentamos os serviços que podem ser contratados no destino e buscamos fazer isso com qualidade, dinamismo e tecnologia, somos apolíticos e parceiros de todas as entidades que promovem o destino. O nosso trabalho é diretamente 
influenciado pelas políticas públicas de desenvolvimento da atividade turística (Gestor 1).

Posso citar as políticas públicas que o órgão vem desenvolvendo ao longo da atual gestão, buscamos modelos consolidados em outros países, somos parceiros em eventos. Infelizmente, com a atual crise financeira do estado, não estamos investindo como deveríamos. Mas acreditamos que em breve essa fase irá passar, e iremos desenvolver estratégias para não só Natal ser um destino inteligente, mas quem sabe implantar em outros destinos do estado (Gestor 5).

A organização que trabalho contribui com ações e estratégias para tornar Natal um DTI, por meio da nossa política de valorização do capital humano, a sustentabilidade nos seus três pilares (econômico, social e ambiental) e a utilização de recursos de forma inteligente (Gestor 10).

De uma perspectiva histórica, há inovações no turismo ao longo dos anos, como o advento das companhias aéreas de baixo custo (low cost), bem como o surgimento de modelos de negócios inovadores como Online Travel Agencies e hospedagens compartilhadas como Airbnb, que afetam o comportamento dos turistas, impactando na oferta turística. Portanto, representam uma ameaça para as empresas e destinos tradicionais quando não acompanham a dinâmica global de inovação.

\section{CONCLUSÕES}

Este estudo objetivou analisar os aspectos do destino turístico Natal/RN na perspectiva de um DTI. A partir de entrevistas com gestores públicos e privados envolvidos na atividade turística local, conclui-se que a cidade está em fase embrionária como um DTI, sendo necessário estabelecer uma integração entre poder público e iniciativa privada, por meio de uma gestão participativa. Ademais, as práticas de DTI ajudam a aumentar a competitividade de um destino quando comparado a destinos turísticos tradicionais. 
Quanto aos indicadores de DTI do modelo INVAT.TUR (2015), entre os aspectos de Governança e Sustentabilidade que precisam ser melhorados, a Prefeitura Municipal, por intermédio da Secretaria de Meio Ambiente e Urbanismo de Natal (SEMURB), retomou o processo de atualização do PDN. O novo plano será segmentado pela participação de órgãos públicos do âmbito municipal e estadual, como a Câmara dos Vereadores de Natal, Ministério Público do Rio Grande do Norte (MPRN), Superintendência do Patrimônio da União no Rio Grande do Norte (SPU), Instituto de Desenvolvimento Sustentável e Meio Ambiente do Rio Grande do Norte (IDEMA), Organizações não Governamentais (ONG), entidades do segmento empresarial, universidades, instituições de pesquisa e movimentos populares (Prefeitura Municipal de Natal, 2019). Foram criados grupos de trabalho para atuar no processo de revisão do PDN, contribuindo com o aprofundamento técnico nos aspectos físico-territoriais e na gestão urbana municipal, divididos em temáticas: Macrozoneamento e Ocupação do Solo, Áreas Especiais, e o Sistema de Planejamento, Gestão e Fundos de Desenvolvimento Urbano (Prefeitura Municipal de Natal, 2019).

Na área de Sistemas de Informação e Conectividade, o SEBRAE vem investindo cerca de $\mathrm{R} \$ 1,3$ milhão em ações de tecnologias no turismo do estado. Os recursos foram investidos na inserção de pequenos negócios turísticos no ambiente digital, principalmente agências de turismo e meios de hospedagem, como ações do Projeto DTI. Conforme o Gestor do Projeto DTI no estado, a primeira fase foi implementada de 2017 a 2019, sendo necessário a continuidade de estratégias e ações. A proposta objetiva melhorar a cadeia produtiva do turismo, com foco em governança, tecnologia, experiências turísticas e sustentabilidade. Entre outros aspectos, o projeto do SEBRAE busca gerar recursos de forma eficiente, garantir mais competitividade no setor, proporcionar experiências de qualidade aos turistas e oferecer acessibilidade (SEBRAE, 2019). 
Já em termos de Inovação, existe um projeto considerado inovador do SEBRAE/RN para o desenvolvimento do turismo local: a Rota da II Guerra Mundial (munícipios de Natal e Parnamirim). O SEBRAE/RN vem apoiando e fomentando esse projeto com o levantamento de pontos de interesse turístico. Com o avanço do projeto, realizou um estudo de viabilidade para implantação de um Centro Cultural no antigo terminal Augusto Severo em Parnamirim/RN, com o apoio da aeronáutica na Base Área de Natal (SETUR, 2019).

Apresentando o cenário da cidade de Natal/RN, este trabalho contribui com a identificação de barreiras e oportunidades para o desenvolvimento de um importante destino turístico nacional como um DTI. Para tanto, é imperativo adotar estratégias fundamentais como elaboração, planejamento e execução de instrumentos e procedimentos que promovam a gestão pública participativa e as práticas governamentais, a implementação de políticas públicas para conscientização da sustentabilidade e valorização do meio ambiente, melhorias na acessibilidade e mobilidade urbana, tornando um ambiente universal e acessível para todos. É necessário, também, investir na elaboração de estratégias para a criação de um ambiente propício à inovação e à inserção de ferramentas tecnológicas indispensáveis para posicionar Natal/RN como DTI.

Como limitações do estudo, é preciso mencionar o número restrito de entrevistados devido à dificuldade de acesso em um momento de transição governamental. Portanto, sugere-se que em estudos futuros seja ampliada a amostra de gestores e atualizados os dados considerando os novos desafios impostos pela pandemia do novo coronavírus. Recomenda-se, ainda, que sejam realizadas investigações de cunho quantitativo sobre a temática, tendo como sujeitos turistas e residentes, a fim de conhecer a percepção desse público sobre os DTI. 


\section{REFERÊNCIAS}

Ávila, A. L., Lancis, E. García, S. Alcantud, A., García, B. \& Muñoz, N. (2015). Informe destinos turísticos: construyendo el futuro. Madrid.

Bardin, L. (2011). Análise de conteúdo. São Paulo: Almedina.

Blanco, J. (2015). Libro Blanco de los destinos turísticos inteligentes: estrategias y soluciones para fomentar la innovación em el turismo digital. Madrid: LID Editorial Empresarial. Disponível em http://www.segittur.es/es/DTI/dti-detalle/Libro-Blanco-Destinos-TursticosInteligentes-/\#.WhStiVWnHIU. Acesso em 16 jul. 2019.

Boes, K.; Buhalis, D., \& Inversini, A. (2015). Conceptualising smart tourism destination dimensions. In I. Tussyadiah and A. Inversini (eds.), Information and Communication Technologies in Tourism 2015. (391-403). Switzerland: Springer.

Buhalis, D. \& Sinarta, Y. (2019). Real-time co-creation and nowness service: lessons from tourism and hospitality. Journal of Travel \& Tourism Marketing, 36(5), 563-582.

Buhalis, D., \& Amaranggana, A. (2014). Smart Tourism Destinations. In: Xiang Z., Tussyadiah I. (eds) Information and Communication Technologies in Tourism 2014 . Springer.

Cacho, A., Mendes-Filho, L., Estaregue, D., Moura, B., Cacho, N., Lopes, F. \& Alves, C. (2016). Mobile tourist guide supporting a smart city initiative: a Brazilian case study. International Journal of Tourism Cities, 2(2), 164-183

Cervo, A. L., \& Bervian, P. A. (1996). Metodologia cientifica. (4a ed.). São Paulo: Makron Books.

Cimbaljević, M., Stankov, U., \& Pavluković, V. (2019). Going beyond the traditional destination competitiveness - reflections on a smart destination in the current research. Current Issues in Tourism, 22(20), 2472-2477. 
Del Vecchio, P., Mele, G., Ndou, V. \& Secundo, G. (2018). Creating value from Social Big Data: Implications for Smart Tourism Destinations. Information Processing and Management, 54, 847-860.

Dencker, A. F. M. Métodos e técnicas de pesquisas em turismo. (4a ed). São Paulo: Futura, 2000.

Denzin, N.K. \& Lincoln, Y.S. (2005) Introduction: The Discipline and Practice of Qualitative Research. In: Denzin, N.K. and Lincoln, Y. S., Eds., Handbook of Qualitative Research, (3rd Edition). Sage, Thousand Oaks, 1-32.

Dirks, S., \& Keeling, M. (2009). A Vision of Smarter Cities: How Cities Can Lead the Way into a Prosperous and Sustainable Future. Somers, NY: IBM Global Business Services. Disponível em ftp://public.dhe.ibm.com/common/ssi/ecm/en/gbe03227usen/ GBE03227USEN.PDF.

Femenia-Serra, F. \& Perea-Medina, M. J. (2016). Analysis of three Spanish potential smart tourism destinations. En 6th International Conference on Tourism - New Challenges and boundaries in tourism: policies, innovations and strategies. Nápoles, Itália.

Flick, U. (2009). Desenho da pesquisa qualitativa. Porto Alegre: Artmed.

Freitas, H. B. B., \& Mendes Filho, L. (2020). Iniciativas de destinos turísticos inteligentes na cidade de Natal-RN: Uma abordagem qualitativa. Rosa Dos Ventos - Turismo e Hospitalidade, 12(4), 997-1016.

Gomes, E. L., Gândara, J. M., \& Ivars-Baidal, J. A. (2017). É importante ser um destino turístico inteligente? A compreensão dos gestores públicos dos destinos do Estado do Paraná. Revista Brasileira de Pesquisa em Turismo, $11(3), 503-536$.

Gretzel, U. (2018). From smart destinations to smart tourism regions. Investigaciones Regionales - Journal of Regional Research, 42, 171-184. 
Gretzel, U., Ham, J., \& Koo, C. (2018). Creating the City Destination of the Future - The Case of Smart Seoul. In Wang, Y. Shakeela, A., Kwek, A., \& KhooLattimore, C. (Eds.). Managing Asian Destinations. Springer, forthcoming.

Gretzel, U., Werthner, H., Koo, C., \& Lamsfus, C. (2015). Conceptual foundations for understanding smart tourism ecosystems. Computers in Human Behavior, 50(1), 558-563,

Instituto Valenciano de Tecnologias Turísticas - INVAT.TUR (2020). Disponível em http://invattur.es. Acesso em 29 set. 2020.

Instituto Valenciano de Tecnologias Turísticas - INVAT.TUR (2015). Manual Operativo para la configuración de destinos turísticos inteligentes. Disponível em http://invattur.gva.es/estudio/manual-operativo-para-la-configuracionde-destinos-turisticos-inteligentes/. Acesso em 15 mar. 2018.

Jasrotia, A. \& Gangotia, A. (2018). Smart cities to smart tourism destinations: a review paper. Journal of Tourism intelligence and Smartness, 1 , 47-56.

Jovicic, D. Z. (2019). From the traditional understanding of tourism destination to the smart tourism destination. Current Issues in Tourism, 22(3), 276-282.

Jurin, E. (2008). Smart Tourism Destinations: a framework for the elaboration of an implementation model. Acta Turistica Nova, 2(1), 123-143.

Luque-Gil, A. M., Zayas-Fernández, B., \& Caro-Herrero, J. L. (2015). Los Destinos Turísticos Inteligentes en el marco de la Inteligencia Territorial: conflictos y oportunidades. Investigaciones Turísticas. 10,1-25.

Mehraliyev, F., Cheng Chu Chan, I., Choi, Y., Koseoglu, M. A. \& Law R. (2020) A state-of-the-art review of smart tourism research. Journal of Travel \& Tourism Marketing, 37(1), 78-91.

Mehraliyev, F., Choi, Y., \& Köseoglu, M. A. (2019). Progress on smart tourism research. Journal of Hospitality and Tourism Technology, 10(4), 522538. 
Mendes Filho, L., Silva, J. C. \& Silva, D. S. (2019). Percepções e perspectivas de destino turístico inteligente: um estudo de caso com a secretaria municipal de turismo em Natal/RN. Revista Turismo: Estudos \& Práticas (RTEP/UERN), 8(1), 98-124.

Ministério do Turismo (2013). Turismo acessível: estudo do perfil de turista pessoas com deficiência. Disponível em http://www.turismo.gov.br/turismo/o_ministerio/publicacoes/downloads_publ icacoes/Estudo_de_dem_turistas_pessoas_com_def_DocCompleto_12.2013.p df. Acesso em 16 jul. 2019.

Ministério do Turismo (2015). Turismo Acessível. Disponível em: http://www.turismo.gov.br/assuntos/5054-turismo-acessivel.html.

Ministério do Turismo. (2018). O futuro do setor está na inovação e sustentabilidade. Disponível em: http://www.turismo.gov.br/\%C3\%BAltimasnot\%C3\%ADcias/1 1873-o-futuro-do-turismo-est\%C3\%A1-naintelig\%C3\%AAncia,-inova\%C3\%A7\%C3\%A3o-e-sustentabilidade.html

NVIVO. (2019). Disponível em: http://www.qsrinternational.com/nvivoportuguese. Acesso em 16 jul. 2019.

Organização Mundial do Turismo. (2004). Desenvolvimento sustentável do ecoturismo. São Paulo: Roca.

Plano Diretor de Natal. (2007). Disponível em https://natal.rn.gov.br/semurb/planodiretor/. Acesso em 16 jul. 2019.

Plataforma de Contratación del Sector Público. (2020). Disponível em https://contrataciondelestado.es. Acesso em 29 set. 2020.

Ramos, A. S. M., Mendes Filho, L. A. M., \& Lobianco, M. L. (2017). Sistemas e tecnologia da informação no turismo: um enfoque gerencial. Curitiba: Prismas.

Sánchez, A. V. (2014). Investigación Científica em Turismo: La experiencia Ibérica, Revista Turismo e Desenvolvimento, 20, 21-29. 
Santos, S. R., \& Gândara, J. M. G. (2016). Destino turístico inteligente: construção de um modelo de avaliação com base em indicadores para planejamento, gestão e controle de destinos histórico-culturais patrimônio da humanidade, analisando o caso de São Luís (Maranhão, Brasil). CULTUR: Revista de Cultura e Turismo, 10(2), 69-79.

Santos, S. R., Souza Neto, V. R., Pereira, L. R. S., Gândara, J. M. G., \& Silva, S. R. X. (2016). Destino Turístico Inteligente: Acessibilidade no Centro Histórico de São Luís - Maranhão, um estudo sobre a reputação Online no TripAdvisor. Marketing \& Tourism Review, 1 (2), 1-27.

Serviço Brasileiro de Apoio às Micro e Pequenas Empresas - SEBRAE. (2019). Disponível em http://www.sebrae.com.br/sites/PortalSebrae/sebraeaz/destinos-turisticosinteligentes,983d59f53b1 bb510VgnVCM1000004c00210aRCRD. Aceso em 16 jul. 2019

Serviço Brasileiro de Apoio às Micro e Pequenas Empresas - SEBRAE. (2016). Destinos Turísticos Inteligentes. Tecnologias de informação e desenvolvimento sustentável. Disponível em: https://m.sebrae.com.br/Sebrae/Portal\%20Sebrae/Anexos/BI_Tur_2016_06_De stinos\%20Tur\%C3\%ADsticos\%20Inteligentes.pdf. Acesso em 15 mar. 2018.

Serviço Brasileiro de Apoio às Micro e Pequenas Empresas - SEBRAE. (2017). Destinos turísticos inteligentes: Saiba o que são os destinos turísticos inteligentes e conheça como o Sebrae atua no setor. Disponível em http://www.sebrae.com.br/sites/PortalSebrae/sebraeaz/destinos-turisticosinteligentes,983d59f53b 1bb510VgnVCM1000004c00210aRCRD. Acesso em 15 mar. 2018.

SETUR - Secretaria de Turismo do RN - (2019). Rio Grande do Norte Informações Gerais. Disponível em http://setur.rn.gov.br/?page_id=4050. Acessado em 05 ago. 2020. 
Silva, E. L. \& Menezes, E. M. (2001). Metodologia da Pesquisa e Elaboração de Dissertação. (3a ed). Florianópolis: Laboratório de Ensino a Distância da UFSC.

Sociedad Estatal para La Gestión de La Innovación y las Tecnologias Turísticas - SEGITTUR. (2016). Norma UNE 178501 - Sistema de gestións de los destinos turísticos inteligentes. Disponível em http://www.segittur.es/es/proyectos/proyecto-detalle/Aprobada-NormaUNE-Sistema-de-Gestin-de-los-Destinos-Tursticos-Inteligentes.-Requisitos

Sociedad Estatal para La Gestión de La Innovación y las Tecnologias Turísticas - SEGITTUR. (2013). Disponível em: http://www.segittur.es/es/DTI/

Sousa, T. C. G., Souza, M. J. B., Rossetto, C. R. \& Ivars-Baidal, J. A. (2016). Análise da transformação de um Destino Turístico Tradicional (DTT) em Destino Turístico Inteligente (DTI) à luz do modelo da SEGITTUR (2013). CULTUR: Revista de Cultura e Turismo,10(2), 86-91.

Thomaz, G. M.; Biz, A. A.; Bettoni, E. M.; Mendes-Filho, L.; Buhalis, D. (2017). Content mining framework in social media: A FIFA world cup 2014 case analysis. Information \& Management, 54, 786-801.

Thomaz, G. M.; Biz, A. A.; Gândara, J. M. G. (2013). Innovación en la promoción turística en medios y redes sociales: Un estudio comparativo entre destinos turísticos. Estudios y Perspectivas en Turismo, 22, 102-119.

Vargas, L. \& Maldonado, G. (2001). Guia para apresentação de trabalhos científicos. 3. ed., Porto Alegre: Programa de Pós-Graduação em Administração - PPGA/UFRGS.

Wilhelm, R. \& Ruhlandt, S. (2018). The governance of smart cities: A systematic literature review. Cities, 81, 1-23. 